\title{
MANEJO DE LA SONDA VESICAL EN EL POST-OPERATORIO DE CIRUGIA VAGINAL
}

\author{
Doctor Rubén Darío Guzmán
}

\section{Fisiología de la micción}

En la micción participan elementos importantes como son el sistema nervioso, la uretra posterior en el hombre y toda la uretra, excepto el centímetro más distal en la mujer, además de la vejiga. La pared abdominal y el piso pélvica desempeñan papel aunque en menor grado.

El cuello vesical verdadero, formado por tejido elástico y músculo vesical, corresponde a toda la uretra en la mujer y a la uretra prostática y membranosa en el varón (3).

El fondo vesical recibe la orina y la almacena a presión baja hasta alcanzar su capacidad máxima, gracias a la acción del esfínter primario llamado también vesical interno; éste impide que la orina se escape por su luz en virtud a la resistencia que presentan sus paredes al fiujo urinario, de manera que si la oposición de sus paredes es completa la presión que se necesitaría para hacer pasar líquido por la luz uretral sería tanto mayor. El tono inherente del músculo liso y del tejido elástico de las paredes uretrales, ayuda a mantener estrecha la luz uretral $\sin$ auxilio del sistema nervioso central; así que la vejiga almacena orina de manera autónoma con gasto insuficiente de energía (1).

Pero no debemos olvidar el papel que tienen los músculos elevador del ano y esfínter uretral externo, que aunque menos importante, no dejan de desempeñar función especial, ya que comprimen circunferencialmente la uretra y la alarga tirándola hacia la vejiga dando por resultado disminuír su calibre, aumentando por lo tanto la tensión de sus paredes, factores todos que tienden a oponerse al paso del líquido a través de la uretra.

Al toser, pujar, realizar un esfuerzo grande, aumenta la presión intravesical y la uretra debe aumentar su resistencia al flujo de orina para impedir que se salga ésta y los músculos estriados, esfinter uretral y elevador del ano, pueden experimentar contracciones reflejas. Son necesarios para terminar o interrumpir súbitamente la micción (5). Pero para una continencia urinaria eficiente, se necesita que la uretra o el esfinter vesical interno se encuentren en buen estado, igualmente que los músculos estriados, porque de nada 
Noviembre-Diciembre 1964

Rev. Col. Obs. y Ginec.

valdría si los primeros no trabajan como debe ser y los segundos se encuentran íntegros. De manera que cuando la presión intravesical es alta, para una buena continencia se necesita que el elevador del ano y el esfínter uretral externo se encuentren íntegros y el esfínter vesical interno normal; si la presión intravesical es baja, sólo se necesitaría buen funcionamiento de este último (2).

Es sabido que el sistema nerviososimpático no participa en el fenómeno de la micción y que la vejiga recibe sus impulsos motores del sistema nervioso para-simpático o cráneo-sacro (S2, S3, S4) y a su vez envía sus sensaciones exteroceptivas (dolor y temperatura) propioceptivas (sensación de plenitud vesical, deseo de orinar), al sistema nervioso central siguiendo las fibras para-simpáticas motoras; así que para que la vejiga se vacie eficazmente, son necesarios el arco medular normal y musculatura vesical íntegra. Al llenarse la vejiga de orina, las terminaciones propioceptivas y exteroceptivas sufren alargamiento; los impulsos aferentes excitan las neuronas motoras inferiores acabando por causar descarga de las mismas; estos impulsos motores nacidos en las neuronas, cursan por las fibras para-simpáticas aferentes, las sinapsis ganglionares y las terminaciones musculares y hacen contraer la musculatura vesical del fondo y cue1lo. El fondo se contrae comprimiendo la orina y a la vez tira del cuello vesical hasta abrirlo logrando salir aqueIla; los músculos elevador del ano y esfinter uretral externo deben relajarse para que pase la orina por la uretra.

\section{Fisiopatología uretro-vesical post-operatoria}

La sonda vesical debe utilizarse con toda la asepsia posible y con el menor traumatismo, sobre todo si se trata de la uretra femenina, ya que por su situación en el periné y por la vecindad con la vagina y el recto y por consiguiente su continuidad directa con el medio exterior, cualquier irritación por traumatismo al emplear una sonda vesical o, por no seguir las normas de asepsia al sondear una paciente, los gérmenes saprofitos que se encuentran en ella, pueden volverse patógenos y producir una complicación infecciosa vesical, uretral y aun renal (6).

La mayoría de los autores recomiendan lavar cuidadosamente la zona alrededor del meato, con un buen detergente como el hexaclorofeno. Luego utilizan un preparado de amonio cuaternario, como el zefirán para así no infringir lo $\mathrm{d}$ i $\mathrm{c} \mathrm{h}$ o anteriormente. Aunque no somos tan estrictos, si tratamos de cumplir un tanto estas normas y aconsejamos pasar la sonda lubricada ya sea con aceite o un anestésico local, como la Xilocaína, utilizando guantes estériles, ya que sin lubricación o por la introducción forzada y brusca de una sonda puede ocasionarse $\mathrm{m} \mathrm{o} \mathrm{le} \mathrm{s} \mathrm{t} \mathrm{i} \mathrm{a} \mathrm{s,} \mathrm{hemorragias}$ uretrales, vías uretrales falsas o incluso perforación de la uretra. Aún más el traumatismo puede ser causa de infección si hay bacterias en la vecindad No encargar esta misión a una enfermera inexperta e irresponsable y aún más, si la realiza en la cama puede in- 
t r o d u c i r la sonda por el recto o por la vagina antes de introducirla en la uretra y así llevar la infección a la vejiga. Por eso aconsejamos practicar el sondeo vesical en la mesa ginecológica. Deben separarse los labios para evitar la contaminación; si la sonda queda colocada para drenaje, se fijará a la misma un tubo y una botella estériles; se utilizarán tubos de gran calibre netamente mayores que la luz de sonda. El tubo de drenaje debe terminar a la entrada de la botella y nunca que flote en la orina recogida; si la orina se derrama contaminará por vía retrógrada.

$\mathrm{Si}$ puede conservarse la orina no infectada debe evitarse el lavado, a menos que se produzca hemorragia. Cuando la orina es purulenta o contiene muchos restos epiteliales puede ser útil practicar lavados acidificantes, aunque a veces no son tolerados por la irritabilidad vesical que se produce en algunas pacientes. Una vez retirada la sonda se le recomienda a la paciente orinar espontáneamente de dos a tres veces y luego medir el residuo miccional post-quirúrgico, el cual consideramos que debe ser menor de $50 \mathrm{cc}$, para dar de alta a la enferma $(7,8,9,10)$.

La infección de las vías urinarias es una complicación que se observa más frecuentemente después de las operaciones vaginales, como son las uretritis traumática simples, la cistitis y las pielonefritis.

La uretritis se debe a sondeos repetidos debido a la irritación que producen los mismos. Aparece escozor y puede haber poliuria si el trígono se encuentra afectado por la irritación. Se presenta con más frecuencia en los casos en que se deja sonda a permanencia. Estos síntomas se eliminan con líquidos y alcalinizando la orina después de que la enferma ha comenzado a orinar. También pueden usarse instilaciones endovesicales de aceite gomenolado tibio. En el Servicio se han presentado varios casos.

La cistitis es muy frecuente después de un sondeo inadecuado, o con sonda permanente, al introducir un organismo en las cateterizaciones; pero la cateterización seguida de hiperdistensión o el dejar orina residual, son los factores etiológicos más importantes. Aparece poliuria, escozor, disuria, acompañado de poca o ninguna elevación de temperatura.

En nuestras pacientes hemos tenido casos de cistitis, aunque con el uso de profiláctico de Gantrisin el porcentaje no es alto.

En cuanto a la pielonefritis, es la complicación más temida. En presencia de sonda suele representar la extensión de la infección desde la parte más baja de las vías urinarias, pero puede depender de un proceso hematógeno. Muchas veces se presenta con escalofríos seguidos de fiebre. En un gran número de casos el escozor y la piuria preceden a la fiebre; ésta generalmente es de tipo agudo, alcanzando una elevación de 39 y medio o más grados por la tarde y regresando a lo normal por las mañanas. Puede emplearse sulfamidas, (gantrisin), alcaīizar la orina, etc. (11). 
Novak sostiene que aunque se cumplan las medidas más asépticas, no se logra impedir casi nunca la aparición de cistitis. También preconiza que si existe alguna infección vesical antes de ser sometida a una intervención vaginal la infección debe tratarse previamente (12).

En cuanto a la retención urinaria como complicación post-operatoria, después de las intervenciones ginecológicas es muy común. Wodruff y TeLinde, hallaron una frecuencia del $51 \%$ en una serie de 257 laparotomías pelvianas en un hospital en el que no se habían tomado medidas especiales para prevenir la retención y una incidencia del $58 \%$ después de operaciones plásticas vaginales, en dos grupos: uno de 57 enfermas en las cuales se habían tomado cuidadosamente las mismas medidas preventivas que tuvieron éxito en las pacientes sometidas a laparotomías y un grupo de control de 62 enfermas en las cuales no se emplearon las medidas mencionadas.

Como quiera que la retención acrecienta la posibilidad de la cistitis y se suma a las molestias post-operatorias de la enferma, es preciso tratar de combatirla por todos los medios. En 1925 se adoptó en el hospital de John Hopkins instilar una solución acuosa de mercurocromo al $0.5 \%$ pero las cistitis químicas eran frecuentes y en realidad no se logró disminuír la incidencia de la necesidad de cateterismo en las pacientes sometidas a plásticas vaginales. Otros autores proponen una solución de ácido acético al $0.25 \%$.
Algunos cirujanos son partidarios del cateter permanente porque evita la hiperdistensión de la vejiga, la orina residual y la infección pero, según una estadística presentada por Brown el porcentaje de orinas infectadas es alto. Novak y Curtis son partidarios del cateterismo repetido y para ello toman como índice la sensación de repleción vesical que experimenta la enferma, en vez de repetir aquellos cada cierto número de horas, sobre todo en casos de laparotomia, aunque no abandonan del todo el catéter permanente en cirugía vaginal. Novak sugiere en c a s o de cateterismos repetidos o de catéter permanente, instilar en la veijga, una vez al día $30 \mathrm{cc}$ de cualquier solución antiséptica débil, c o mo mercurocromo al $0.5 \%$ o de nitrato de plata al uno por mil. En caso de catéter a permanencia recomienda acidificar el medio, impidiéndose así la formación de costras y la obstrucción del aparato que podría producir el sedimento urinario y si la reducción de la orina residual se verifica con demasiada lentitud, emplea cloruro de urecolina, lo cual puede suprimir la sonda en algunas ocasiones o por lo menos disminuír el tiempo de permanencia de la sonda vesical (12).

En el Departamento de Obstetricia y Ginecología del Hospital San Juan de Dios, hemos usado en algunos casos Prostigmine i, m. para disminuír el residuo vesical con buen resultado. No hemos empleado soluciones antisépticas endovesicales, ya que creemos que con el empleo del Gantrisin se logra prevenir un tanto el desarrollo de complicaciones post-operatorias vesicales. 
En todos los casos hemos usado sondas de Foley a permanencia y en varios hemos sondeado a necesidad si hacen retención una vez retirada y en otros hemos vuelto a aplicar nuevamente la sonda de Foley durante 24 horas más, para luego retirarla y esperar que orinen espontáneamente dos o tres veces para luego medir el residuo miccional. En caso de que éste sea alto, más de $50 \mathrm{cc}$, en algunas ocasiones colocamos nuevamente la sonda o esperamos que vuelvan a orinar espontáneamente, para posteriormente medir el residuo vesical. $\mathrm{Si}$ es menor de la cifra anotada, damos de alta a la paciente.

Referente a los ejercicios vesicales, los hemos practicado en unas pacientes y en otras no. Las veces que los hemos realizado ordenamos cerrar la sonda vesical por tres horas y abrir durante una hora varias veces al día; éstos ejercicios los realizamos uno o dos días antes de retirar la sonda vesical. Somos partidarios de estos ejercicios, pues con ellos se ejercita la vejiga a ir recobrando poco a poco su tono y contribuír en esa forma a evitar la retención post-operatoria.

Uno de los motivos de consulta inicial de las pacientes de este trabajo, fue el de la incontinencia urinaria de esfuerzo y en los otros casos de sensación de cuerpo extraño fuera de los genitales externos.

Según Jack Lapides (79), la incontinencia urinaria de esfuerzo ocurre cuando por una u otra razón, las paredes uretrales no guardan una aposición tan íntima como en circunstancias norma- les y disminuye la resistencia intrauretral al flujo de la orina. Afirma que se ha comprobado que el estiramiento longitudinal de la uretra aumenta la resistencia intrauretral. En experimentos recientes se comprobó que al disminuír la longitud de la misma por diversos métodos, baja la resistencia dentro del conducto. En algunos pacientes con incontinencia urinaria de esfuerzo la longitud de la uretra está disminuída en las posiciones supina y de pie; en otros, en las de supina solamente; en muchos casos el acortamiento se acompaña de disminución de la resistencia interna. Ahora bien; en una mujer con raquianestesia, la longitud de la uretra y su presión interna disminuyen y sin embargo no hay incontinencia porque los músculos estriados del piso pélvico ayudan a mantener la tensión de la pared uretral y por ello la resistencia intrauretral.

El estudio cistométrico muestra una vejiga normal, excepto por la incapacidad de mantener la continencia al realizar esfuerzos. La presión intrauretral se halla por debajo de lo normal y por debajo de la presión intravesical suscitada durante el esfuerzo. Cuando la paciente cambia de la posición supina a la erecta quizá se advierte disminución de la longitud uretral. EI examen uretroscópico es normal. Sostiene este autor que cualquier procedimiento que aumente la resistencia puede ser beneficioso si la finalidad de la intervención quirúrgica es la de cstirar la uretra y así aumentar la resistencia intrauretral al disminuír la luz del conducto. Por eso cuando se 
practica una corrección del uretrocistocele, se alarga la uretra inadvertidamente y mejora la incontinencia de esfuerzo.

Otros autores sostienen que la incontinencia urinaria de esfuerzo se debe más que a la dilatación del esfinter, a los cambios del ángulo formado entre el trígono y la uretra. Estudios indican que el ángulo formado es abierto hacia adelante; si el trígono desciende ese ángulo desaparece o inclusive puede invertirse. Esto sucede con mucha frecuencia en el prolapso en que al descender la vejiga, hace cambiar el ángulo y la estática del aparato urinario, produciéndose dicha incontinencia.

La enferma con incontinencia urinaria de esfuerzo presenta expulsión de orina al realizar un ejercicio liviano, como ponerse en puntillas o intenso como levantar un objeto pesado. $\mathrm{Si}$ la vejiga no está distendida no la presenta aunque realice grandes esfuerzos.

\section{Orientación}

Hasta la fecha no existe un criterio definido sobre el retiro de la sonda vesical en las operadas de cirugía vaginal. Los textos de técnica quirúrgica ginecológica consultados, no presentan uniformidad de criterio a este respecto. Unos aconsejan retirar la sonda vesical determinado día, u s a n do o instilando endovesicalmente determi- nada droga, pero las complicaciones infecciosas y las retenciones urinarias se siguen presentando sin que se sepa el por qué. Nosotros en el Servicio de Obstetricia y Ginecología del Hospital San Juan de Dios, hemos tratado de estudiar de una manera lo más eficiente, sin seleccionar casos especiales, contemplando toda clase de cirugía vaginal, en que tengamos de por medio la vejiga, no usando la mayoría de las veces antibióticos de ninguna índole, (siempre y cuando que no se presente una infección post-quirúrgica) pero sí empleando un antiséptico urinario (tipo Gantrisin), en la mayoría de las pacientes y tratando de seguir todas las normas de asepsia debidas, con el objeto de buscar una conducta lo más satisfactoria posible, aunque no ideal, en cuanto a la retirada de la sonda vesical en las distintas intervenciones vaginales. Creemos que con el Gantrisin aminoramos el factor irritativo producido por la sonda vesical, el cual puede ser causa de infección posterior.

\section{Material y métodos}

Se estudiaron 129 pacientes de las cuales consultaron 42 por incontinencia urinaria de esfuerzo y 87 por sensación de cuerpo extraño fuera de los genitales externos, en un lapso de tiempo comprendido entre el 18 de marzo al 21 de octubre, 1960. Todas presentaron diversos grados de prolapso genital, distribuídos así: 


\begin{tabular}{|c|c|c|c|c|c|c|}
\hline Uretrocistocele & II & Uretrocistocele & III & & Uretrocistocele & III \\
\hline & 49 & Histerocele & III & 1 & Histerocele & II \\
\hline Rectocele & II & Rectocele & II & & Rectocele & III \\
\hline Uretrocistocele & III & Uretrocistocele & $\mathrm{I}$ & & Uretrocistocele & I \\
\hline Histerocele & II & Histerocele & III & 1 & Histerocele & II \\
\hline Rectocele & II & Rectocele & I & & Rectocele & II \\
\hline $\begin{array}{l}\text { Prolapso ge- } \\
\text { nital }\end{array}$ & II 17 & $\begin{array}{l}\text { Prolapso ge- } \\
\text { nital }\end{array}$ & III & 5 & & \\
\hline
\end{tabular}

Llamamos prolapso genital de II, cuando la vejiga, el recto y el útero descienden hasta ras de la vulva y prolapso genital de III, cuando estos mismos elmentos descienden más allá de la vulva.

La edad osciló entre los 21 y los 80 años. Se practicaron las siguientes intervenciones:

Colporrafia Ant. con Perineorrafia: 49 Operación de Manchester-Fothergill: 34 Histerectomía vaginal:

En las dos primeras clases de intervenciones se practicó raspado uterino previo, procedimiento que realizamos de rutina en el servicio, ya que descartamos de hecho el embarazo.

En las operaciones de plastia vaginal usamos sonda de Foley números 16,18 y en pocas ocasiones la número 20 , ya que consideramos que estos números son los más indicados en esta clase de cirugía. No utilizamos la sonda de Pezer, pues la primera es más cómoda, más estable y menos traumática. Tampoco recurrimos a la de Nelaton, pues la de Foley por su aditamento especial, el balón, ofrece más seguridad. Pero cuando sondeamos a una paciente que ha hecho retención, recurridos a la sonda de Nelatón o a la metálica.

Cuando practicamos ejercicios vesicales los verificamos uno o dos días antes de retirar la sonda. En algunas ocasiones instilamos endovesicalmente aceite gomenolado tibio 10 a $20 \mathrm{cc}$ antes de retirarla o al sondear a la paciente si ha retenido. Damos de alta a la paciente cuando el residuo postmiccional es menor de $50 \mathrm{cc}$.

Con alguna frecuencia tuvimos complicaciones de tipo infeccioso, como necrosis o dehiscencias de las suturas, hematomas o abscesos de la cúpula vaginal sin que sea tema de detallar en este trabajo, por considerar que no cabe dentro del estudio propuesto. 
RESULTADO: COLPORRAFIAS ANTERIORES: 49

\begin{tabular}{|c|c|c|c|}
\hline $\begin{array}{l}\text { Dias en que } \\
\text { se retiró la } \\
\text { sonda }\end{array}$ & $\begin{array}{l}N^{0} \text { de } \\
\text { casos }\end{array}$ & $\begin{array}{l}\text { Ejercicios } \\
\text { vesicales }\end{array}$ & Resultados: \\
\hline 0 & 2 & - & Retención en ambos. \\
\hline \multirow[t]{2}{*}{1} & 3 & - & $\begin{array}{l}\text { Retención por } 2 \text { días. } 2 \text { sin complica- } \\
\text { ciones. }\end{array}$ \\
\hline & & -+ & $\begin{array}{l}\text { Retención por } 2 \text { días. } 3 \text { sin complica- } \\
\text { ciones. }\end{array}$ \\
\hline 2 & 4 & Todos: $(-)$ & Sin complicaciones. \\
\hline 3 & 17 & +++ El resto: - & Retención por 2 días. \\
\hline \multirow[t]{2}{*}{4} & 17 & + & Sin complicaciones. \\
\hline & & ++++ El resto: - & $\begin{array}{l}\text { Retención por } 2 \text { días, } 3 \text { casos sin com- } \\
\text { plicación. }\end{array}$ \\
\hline \multirow[t]{2}{*}{5} & 4 & + & Sin complicaciones. \\
\hline & & ++- & Retención por 3 días. \\
\hline 6 & 1 & - & \\
\hline 7 & 1 & - & \\
\hline
\end{tabular}

Total 49

Se intervinieron 49 enfermas de colporrafias anteriores y perineorrafia. Se presentó retención urinaria cuando no se aplicó sonda y cuando se retiró al $1^{\circ}, 2^{\circ}, 4^{\circ}, 5^{\circ}$ y $7^{\circ}$ día. De éstos la mayor retención fue por tres días, cuando se retiró la sonda al 7 día.
No hubo complicación en 17 pacientes cuando se retiró la sonda al tercer día. En la mayoría de los pacientes no se realizaron ejercicios vesicales antes de retirar la sonda. 
OPERACION： MANCHESTER-FOTHERGILL：34

\begin{tabular}{|c|c|c|c|}
\hline $\begin{array}{l}\text { Dias en que } \\
\text { se retiró la } \\
\text { sonda }\end{array}$ & $\begin{array}{l}\text { No de } \\
\text { casos }\end{array}$ & $\begin{array}{l}\text { Ejercicios } \\
\text { vesicales }\end{array}$ & Resultados: \\
\hline 2 & 4 & ---- & Sin complicaciones. \\
\hline 3 & 7 & $\begin{array}{l}+- \\
+ \\
+---\end{array}$ & $\begin{array}{l}2 \text { casos de retención por } 3 \text { días. } \\
\text { Retención por } 7 \text { días. } \\
4 \text { casos sin complicaciones. }\end{array}$ \\
\hline 4 & 10 & $\begin{array}{l}- \\
-- \\
+ \\
+++---\end{array}$ & $\begin{array}{l}\text { Retención por } 1 \text { día. } \\
2 \text { casos de retención por } 2 \text { días. } \\
\text { Retención por } 6 \text { días. } \\
6 \text { casos sin complicaciones }\end{array}$ \\
\hline 5 & 7 & $\begin{array}{l}- \\
+++---\end{array}$ & $\begin{array}{l}\text { Retención por } 3 \text { días. } \\
6 \text { casos sin complicaciones. }\end{array}$ \\
\hline 6 & 1 & - & Sin complicación. \\
\hline 7 & 1 & + & Retención por 1 día. \\
\hline 8 & 2 & -- & Sin complicaciones. \\
\hline 9 & 1 & & Sin complicaciones. \\
\hline 10 & 1 & - & Sin complicaciones. \\
\hline
\end{tabular}

Total 34

Se intervinieron 34 enfermas de Manchester-Fothergill. Se presentó retención urinaria cuando se retiró la

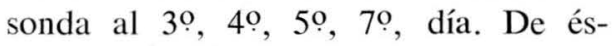
tos la mayor retención fue por seis días al retirar la sonda al $4^{\circ}$ día.

El menor número de complicaciones se obtuvo al retirar la sonda al 50 día en un grupo de 7 pacientes, pues solamente se presentó una retención por tres días y seis casos sin complicaciones.

En un gran número de pacientes no se practicaron ejercicios vesicales antes de retirar la sonda vesical.

El motivo por el cual se dejó la sonda por más de 7 días, se debió a complicaciones infecciosas como dehiscencia o necrosis de las suturas. 
RISTERECTOMIA VAGINAL: 46

\begin{tabular}{|c|c|c|c|}
\hline $\begin{array}{l}\text { Dias en que } \\
\text { se retiró la } \\
\text { sonda }\end{array}$ & $\begin{array}{l}N^{0} \text { de } \\
\text { casos }\end{array}$ & $\begin{array}{l}\text { Ejercicios } \\
\text { vesicales }\end{array}$ & Resultados: \\
\hline 0 & 1 & - & Retención por 11 días. \\
\hline 1 & 1 & - & Retención por 7 días. \\
\hline 3 & 8 & -- & Sin complicación. \\
\hline & & ------ & 2 casos retención por 1 día. \\
\hline 4 & 9 & $\begin{array}{l}+ \\
- \\
-+1++1-1-n\end{array}$ & $\begin{array}{l}6 \text { casos sin complicaciones. } \\
\text { Retención por } 7 \text { días. }\end{array}$ \\
\hline 5 & 10 & $\begin{array}{l}- \\
- \\
+ \\
- \\
+-\end{array}$ & $\begin{array}{l}7 \text { casos sin complicaciones. } \\
\text { Retención por } 8 \text { días. } \\
\text { Retención por } 2 \text { días. } \\
\text { Retención por } 3 \text { días. }\end{array}$ \\
\hline 6 & 6 & $\begin{array}{l}- \\
----- \\
----\end{array}$ & $\begin{array}{l}2 \text { casos retención por } 4 \text { días. } \\
\text { Retención por } 2 \text { días. } \\
5 \text { casos sin complicaciones. }\end{array}$ \\
\hline 8 & 3 & $\begin{array}{l}- \\
- \\
-\end{array}$ & $\begin{array}{l}\text { Sin complicaciones. } \\
\text { Retención por } 2 \text { días. } \\
\text { Retención por } 3 \text { días. }\end{array}$ \\
\hline 9 & 1 & - & Sin complicación. \\
\hline 10 & 1 & - & Sin complicación. \\
\hline 11 & 2 & -- & Sin complicación. \\
\hline Total & 46 & & Sin complicación. \\
\hline
\end{tabular}

Se intervinieron 46 enfermas de histerectomía vaginal. Hubo retención urinaria cuando no se aplicó sonda o cuando se retiró al $1^{\circ}, 3^{\circ}, 4^{\circ}, 5^{\circ}, 6^{\circ}$ y 80 días.

La mayor retención fue por 11 días, cuando no se aplicó sonda y cuando si se realizó; la mayor retención fue por 8 días en un grupo de 10 pacientes al retirarla al 5 día.

El menor número de complicaciones se notó al retirar la sonda al 4 o día en un grupo de 9 pacientes, pues hubo dos casos de retenciones por un día y por 7 días. Siete casos sin complicaciones.

En la mayoría de los casos no se practicaron ejercicios vesicales antes de retirar la sonda.

El motivo por el cual se dejó la sonda por más de siete días se debió a necrosis, dehiscencias de las suturas, hematomas o abscesos de cúpula vaginal o complicaciones de orden general. 


\section{Resumen y conclusiones:}

Se presenta una serie de 29 enfermas las cuales consultaron: unas por incontinencia urinaria de esfuerzo y otras por sensación de cuerpo extraño fuera de los genitales externos. Al examen ginecológico se encontró diversos grados de prolapso genital. Fueron intervenidas, unas de colporrafia anterior y perineorrafia; otras de Manchester-Fothergill y otras de Histerectomía vaginal. En las dos primeras clases de intervenciones se practicó raspado uterino previo. Se aplicó sonda de Foley números 16, 18 y en pocos casos número 20. Arbitrariamente se retiró la sonda en determinado día. Se analiza una de las complicaciones; la retención urinaria. En varias pacientes se realizaron ejercicios vesicales antes de retirar la sonda vesical.

Como puede observarse en los cuadros de los resultados, el día ideal para retirar la sonda en las operaciones de colporrafias es el 3er. día; en las operaciones de Manchester-Fothergill, el $5^{\circ}$ día y en las de histerectomía va- ginal, el 4o día, ya que proporcionalmente se presentaron el menor número de retenciones en el mayor grupo de pacientes.

En las coiporrafias muy pocas complicaciones se produjeron, así como fue más frecuente en las intervenciones de Manchester-Fothergill e histerectomía vaginal.

Los ejercicios vesicales tuvieron un valor relativo. No se apreciaron modi. ficaciones en cuanto a la retención urinaria, en relación a las diversas técnicas empleadas por los cirujanos.

Dado que se trata de una serie muy corta de intervenciones realizadas hasta la fecha, no es posible obtener conclusiones definitivas, por lo tanto debe considerarse como una comunicación preliminar mientras seguimos estudiando este tema con un número mayor de casos con el fin de buscar de manera exacta cuál es el día ideal para retirar la sonda en las intervenciones vaginales. 


\section{BIBLIOGRAFIA}

1. LAPIDES JACK. Fisiología de la micción. Clínicas Médicas de Norte América. Pág. 1.629. 1959 .

2. LAPIDES JACK: Structure and function of Internal Vesical Sphincter. J. Urol. 80: 341.1948.

3. BARNES R. W. y WILSON W. W.: Reconstruction of urethra with tube from Bladder Flop. Urol. \& Cutan. Rev. 53: 604. 1949.

5. LAPIDES JACK, SWEET R. B. y LEWUIS L. W.: Role Striated Muscle in Urination. J. Urol. 77: 247. 1947.

6. DESAUTLS R. E. y HARRISON J. HARTWELL: Uso inadecuado de la Sonda Uretral. Clínicas Médicas de Norte América. Pág. 1.573. 1959.

7. QUIMBY W. C.: UROLOGICAL SURGERY: The urethral catheter. New England J. Med. 223: 543-546, 1940.

$7 A$ GUZE L. B. y BEESON P. B.: Observations on reliability and safety of Blader catheterizations for bacteriologyc study of urine.

8. BUDINGTON E. T. y GROVES R. C.: Management of Catheter Drainage. J. Urol, 62: 387-393, 1949.

9. KASS E. H. y SOSSEN H. S.: Prevention of Infection of Urinary Tract. In Presence of Indwelling Catheters. J. A. M. A. 169: 1181-1183. 1959.

10. BEeson P. B.: Case Against The Catheter. A. M. J. Med. 24: 1-3, 1958.

11. TELINDE RICHARD W.: Ginecología Operatoria. Cuidados post-operatorios y complicaciones. 58-62. 1958.

12. EVERET H.: Trastornos frecuentes de los órganos urinarios de la mujer. Tratado de Ginecología de Novak. 830. 1958. 